\title{
CORRIGENDUM
}

\section{Association of the NRG1 gene and schizophrenia: a meta-analysis}

MR Munafò, DL Thiselton, TG Clark and J Flint

Molecular Psychiatry (2006) 11, 613. doi:10.1038/sj.mp.4001840

Correction to: Molecular Psychiatry (2006) 11, 539-546. doi:10.1038/sj.mp.4001817

Following the online publication of the above article, the authors noticed the following error: in the footnote to Table 2, 'rs32016134' is incorrect and should read 'rs1462906', which is at the bp position 32016134 of human genome assembly May 2004. 